\title{
Effect of Slope Gradient on Erosion Evolution Process at Microtopographic Tillage Soil Surfaces
}

\author{
Wei Zheng1, Hui Zhang1, Yun Jiang², Xin Zhang1, Yawen Tong1, Qingfeng Zhang1* \\ ${ }^{1}$ College of Natural Resources and Environment at Northwest A \& F University, Yangling, China \\ ${ }^{2}$ Department of Foreign Languages at Northwest A \& F University, Yangling, China \\ Email: *zhqf@nwsuaf.edu.cn
}

How to cite this paper: Zheng, W., Zhang, H., Jiang, Y., Zhang, X., Tong, Y.W. and Zhang, Q.F. (2019) Effect of Slope Gradient on Erosion Evolution Process at Microtopographic Tillage Soil Surfaces. Journal of Geographic Information System, 11, 481-492.

https://doi.org/10.4236/igis.2019.115029

Received: August 23, 2019

Accepted: September 24, 2019

Published: September 27, 2019

Copyright $\odot 2019$ by author(s) and Scientific Research Publishing Inc. This work is licensed under the Creative Commons Attribution International License (CC BY 4.0).

http://creativecommons.org/licenses/by/4.0/

(c) (†) Open Access

\begin{abstract}
Slope gradient is one of the critically important factors which drive the erosional response of microtopographic surfaces. This study investigates the effect of slope gradient on the evolution of erosion under accumulative rainfall in laboratory experiments and calculates critical slope values that help evaluate land suitability for farming and similar purposes. Dynamics of accumulative runoff, accumulated sediment and their rates in each erosion stage are studied when the slope gradient varies. The critical slope value for the microtopographic surface was calculated according to the relationship between the sediment yield and slope gradient. The amount of eroded soil downhill in each erosion stage was calculated using DEM data of point cloud. Results show that 1) a steeper slope would increase cumulative runoff; 2) cumulative sediment increases rapidly initially and then stabilizes with the increase of slope; 3$)$ the critical slope value for the whole erosion is determined as $10^{\circ}$. The findings of the dynamics of interrill erosion and sediment characteristics are useful information for future research of erosion prediction and conservation of soil and water in the Chinese Loess Plateau.
\end{abstract}

\section{Keywords}

Critical Slope Values, Cumulative Runoff, Cumulative Sediment, Interrill Erosion, Rate of Erosion

\section{Introduction}

Slopping farming land accounts for nearly two-third of the total land of the Loess Plateau in China, and the average annual erosive modulus is as high as $25,000 \mathrm{t} \cdot \mathrm{km}^{-2} \cdot \mathrm{a}^{-1}[1]$. This situation makes the Loess Plateau a major source of 
soil losses, and slope plays a key role in the evolution of eroded soil surface in this loessial region. In order to illustrate the erosion processes, continual scientific efforts have been made to investigate the relationship between slope and erosion, which have been represented by many soil erosion models from the early Zingg from 1940's, to later Smith, Whitt, Musgrave, USLE and WEPP. Some consensus has been arrived at that the slope is an important factor influencing runoff, has a correlation with erosion rate and runoff rate [2] [3] [4] [5], influences the duration of time for each stage of erosion [6], and governs soil erosion [7] [8] [9]; and runoff and erosion tend to increase when a rainfall event occurs on a steeper surface at a critical slope ranging between $5^{\circ}$ and $25^{\circ}$ [10] [11] [12] [13]. Besides, there is a general consensus that contour tillage (CT), as an agricultural farming practice widely used in the Chinese Loess Plateau, has favorable soil and water conserving effect [14] [15]. However, the optimal critical slope for appropriate tillage remains unidentified.

The microtopographic surfaces are created by using farm tillage tools to form undulating terrains which comprise a mixture of soil grains, aggregates and clods, and whose height variance is rather small [16]. When the force of rainfall and runoff causes soil detachment and sediment transport, and creates depressions to store water, the surface roughness changes occur, which have an impact on the evolution of soil erosion, so to throw light on the dynamics of surface microtopography is critically important to understanding erosion [17] [18].

The evolution of erosion is a complicated multi-scale profile changing process. The soil erosion patterns show irregularities when they are observed on different scales. For example, DEMs are nowadays used to produce basic data for the soil erosion study, and fractal and anisotropic properties could be more prominent and distinct with a higher grid resolution used [14]. Therefore, the findings and conclusions made based on a macro scale don't apply to solve issues relevant here on a micro scale. And the previous study area was often set on the scale of the watershed and mainly focused on the stage of interrill erosion, but few related studies were carried out on the microtopographic scale, i.e. at an area-limited slope with millimeter resolution DEM data. This work approaches only one factor, i.e. slope gradient and we anticipate more factors and indices will be covered in our future research. The purpose of this effort is to shed light into the microroughness and hydrological responses during the evolution of erosion, so as to generate soil erosion models on the microtopographic scale and examine the critical slope value, which will be instrumental in land protection, soil erosion prediction and land suitability classification.

\section{Materials and Methods}

\subsection{Preparation of Soil Surfaces}

The soil used in the experiment was collected from a plough layer $(0-20 \mathrm{~cm})$ from tilled farmland surfaces in Yangling, Shaanxi province, located at the southern edge of the Loess Plateau $\left(107.56^{\circ}-108.08^{\circ} \mathrm{E}, 34.14^{\circ}-34.20^{\circ} \mathrm{N}\right.$, and an 
elevation of 435 - $563 \mathrm{~m}$ ), a warm temperate semi arid zone affected by the monsoon. Long-term annual rainfall at the study site ranges between $635.1 \mathrm{~mm}$ and $663.9 \mathrm{~mm}$, and most occurs in summer. The mean annual temperature is $12.9^{\circ} \mathrm{C}$. The loutu soil (Earth-cumuli-Orthic Anthrosol) is gray brown, loose and granular with silty sand aggregates. The bulk density is $1.30 \mathrm{~g} \cdot \mathrm{cm}^{-3}$. The basic physical texture of soil is shown in Table 1.

Air-dried soil was crushed and passed through a $10 \mathrm{~mm}$ sieve, and soil tanks $(2.0 \mathrm{~m} \times 1.0 \mathrm{~m} \times 1.0 \mathrm{~m})$ were constructed for the study and each was packed with $10 \mathrm{~cm}$ layers of soil to a depth of $100 \mathrm{~cm}$. Each soil layer was raked even before packing the next layer to ensure uniformity of the soil structure, and the bulk density was controlled at $1.30 \mathrm{~g} \cdot \mathrm{cm}^{-3}$ (a mean outdoor bulk density). After the filling, the soil surface was contour tilled to form rows of furrows (Figure 1). Linear sloped surfaces were used as control (CK). The tanks subsequently stood for 48 hours.

\subsection{Design of Experiment}

The laboratory experiment was carried out at the National Soil Erosion and Dryland Farming Laboratory in China. A rainfall simulator was mounted and the downward nozzles placed and adjusted at a height of $18 \mathrm{~m}$, which ensured terminal drop (tap water) velocity. The nozzles could cover an area of $27 \mathrm{~m} \times 18$ $\mathrm{m}$ and rainfall uniformity was higher than $90 \%$ [19].

\subsubsection{Pre-Rain}

Prewetting was conducted on the soil surfaces with a rainfall intensity at 30

Table 1. Aggregate size distribution of the sample soil $(0-20 \mathrm{~cm})$.

\begin{tabular}{cccccccc}
\hline Aggregate size/mm & $<0.001$ & $0.005-0.001$ & $0.01-0.005$ & $0.05-0.01$ & $0.25-0.05$ & $>0.25$ & Clay \\
\hline Weight percentage/\% & 36.28 & 12.89 & 6.88 & 41.13 & 2.7 & 0.12 & 56.05 \\
\hline
\end{tabular}
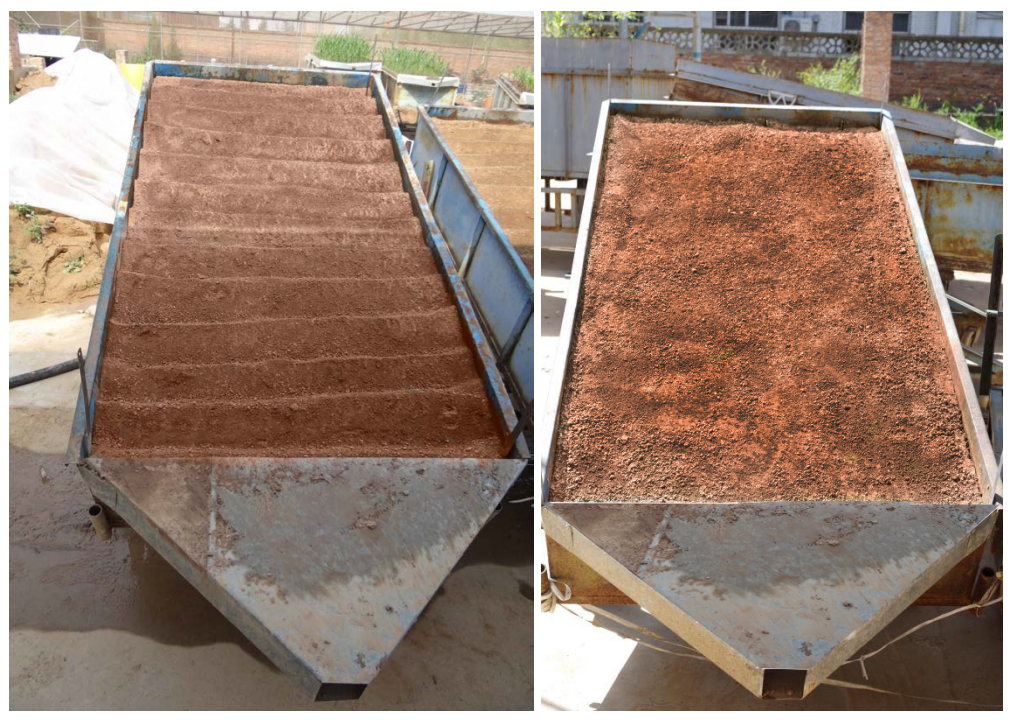

Figure 1. Contour tillage measure (left) and controlled linear slope (right). 
$\mathrm{mm} \cdot \mathrm{h}^{-1}$ applied until surface flow occurred. The duration lasted about $10 \mathrm{mi}-$ nutes with a purpose to consolidate loose soil particles, maintain consistent soil moisture with certain stable water content, and reduce the spatial variability of soil surfaces. Then the surfaces were covered with plastic sheet after the pre-rain to keep the water content of soil, and stood for 24 hours.

\subsubsection{Rainfall Experiment}

The slope gradient of the soil tanks was set at $5^{\circ}, 10^{\circ}, 15^{\circ}$ or $20^{\circ}$, respectively. The rainfall intensity was set at $90 \mathrm{~mm} \cdot \mathrm{h}^{-1}$, which represented a strongest 30 minute storm which takes place once every 30 years in Yangling of Shaanxi.

A simulation rainfall experiment was carried out to apply consecutive artificial rainfall in different events and in different erosion stages, i.e. initial phase, splash erosion, sheet erosion and interrill erosion [20]. During the splash erosion stage, soil particles detached and transported by raindrop splash were collected on splash boards. When a rainfall event proceed, each flow generation duration was documented, runoff was collected, collected at 30 second intervals, and weighted, and then was left to stand for overnight. After the upper clear fluid was separated, the rest soil sample was put into an oven (at $105^{\circ} \mathrm{C}$ ) to be dried and weighted again for calculation of the sediment and runoff. The runoff velocity was measured using a dyed calcium chloride solution and two conductivity probes placed a known distance apart.

\subsubsection{Points Data Processing}

A 3-D terrestrial laser scanning system (Leica, the vertical error less than $1 \mathrm{~mm}$ ) was mounted to scan the surfaces before and after a rainfall event, and cloud data of point elevations for different erosion stages were obtained. The information from each scan was converted into a set of $(x, y, z)$ coordinates which were imported into ESRI ArcGIS software (see: https://www.esri.com) to create the corresponding high resolution $(6 \mathrm{~mm} \times 6 \mathrm{~mm})$ digital elevation models (DEMs) [14]. Subsequently, the 3-D representation of the soil surface microrelief was acquired, and then the 2-D projected area, 3-D surface area and 3-D surface volume for different erosion stages were calculated accordingly. The 3-D surface area is a 3-D representation by point cloud of a surface area of a region of interest selected on the tested slope and the 2-D surface area is an area or image of the region of interest projected on a plane of a certain height. The 3D surface volume is defined as the volume of the region of interest which is between a given reference plane and the upslope of the surface.

SPSS 22.0 was run for regressional statistics and Origin 8.0 was used for mapping.

\section{Results and Analysis}

\subsection{Runoff}

Runoff initiation time for soil surfaces with different slope gradients was respectively, $12.25 \mathrm{~s}\left(5^{\circ}\right), 8.75 \mathrm{~s}\left(10^{\circ}\right), 5.25 \mathrm{~s}\left(15^{\circ}\right)$ and $3.25 \mathrm{~s}\left(20^{\circ}\right)$. And it would de- 
crease for a steeper slope. The runoff initiation for a $20^{\circ}$ slope surface occurred 2.8 times as earlier as that for a $5^{\circ}$ slope.

Figure 2(a) shows that through the whole rainfall event, the cumulative runoff for four different slopes kept increasing, and the cumulative runoff at a steeper slope tended to increase more; each stage for erosion tended to occur sooner and the interrill erosion stage tended to last longer. The cumulative runoff was greatest on the $10^{\circ}$ surface during the splash erosion; it lasted longest on the $15^{\circ}$ surface and for the shortest time on the $10^{\circ}$ surface during the sheet erosion while their cumulative runoff peaked nearly at the same time; during interrill erosion, runoff lasted longest and cumulative runoff was greatest on the $15^{\circ}$ surface.

Through the whole rainfall event, the evolution of runoff flow velocity for different slopes presented similar patterns for change (Figure 2(b)). As the rainfall was applied, the runoff rate was $0 \mathrm{~L} \cdot \mathrm{min}^{-1}$ when the runoff was yet to generate; when the runoff began to generate, the runoff rate increased quickly until it reached a relatively stable state. At a same rainfall intensity, the runoff velocity would be greater at a steeper slope, and in all cases it would increase rapidly first and then steadied off. An SPSS regression simulation predicted that the relationship between rainfall and cumulative runoff could be best represented by the Equation (1):

$$
S_{\text {runoff }}=b_{0}+b_{1} x+b_{2} x^{2}+b_{3} x^{3}
$$

where $b_{0}, b_{1}, b_{2}, b_{3}$ are regression coefficients, $S_{\text {runoff }}$ cumulative runoff $\left(\times 10^{-2} \mathrm{~L}\right)$ and $x$ rainfall $(\mathrm{mm})$.

\subsection{Sediment Yield}

During the rainfall event, the evolution of sediment mass and sediment yield rate for different slope gradients showed similar patterns (Figure 3). Through the

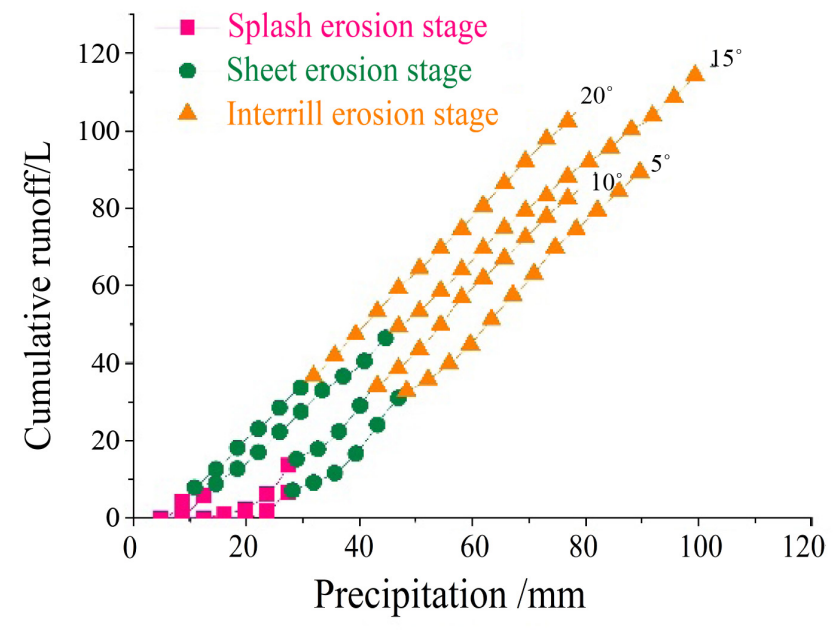

(a)

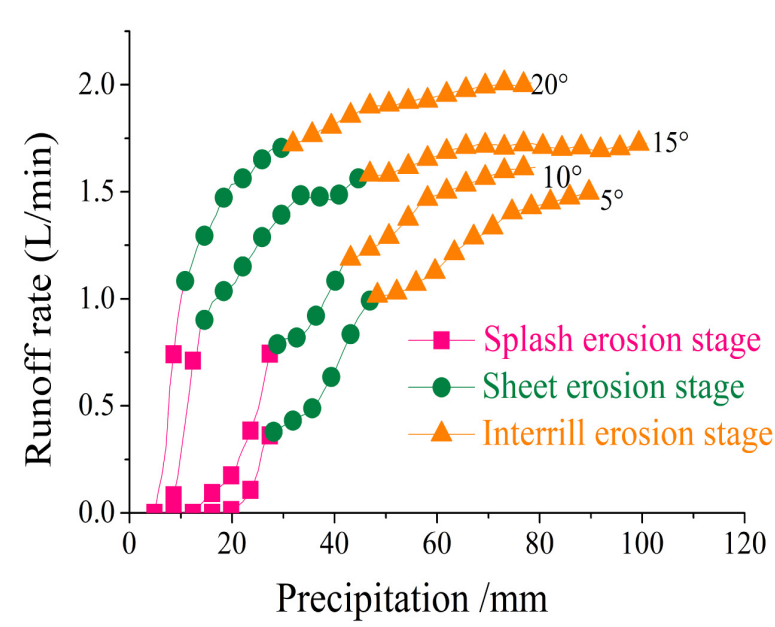

(b)

Figure 2. Evolution of cumulative runoff and runoff rate as a function of cumulative rainfall for different slope gradients. 


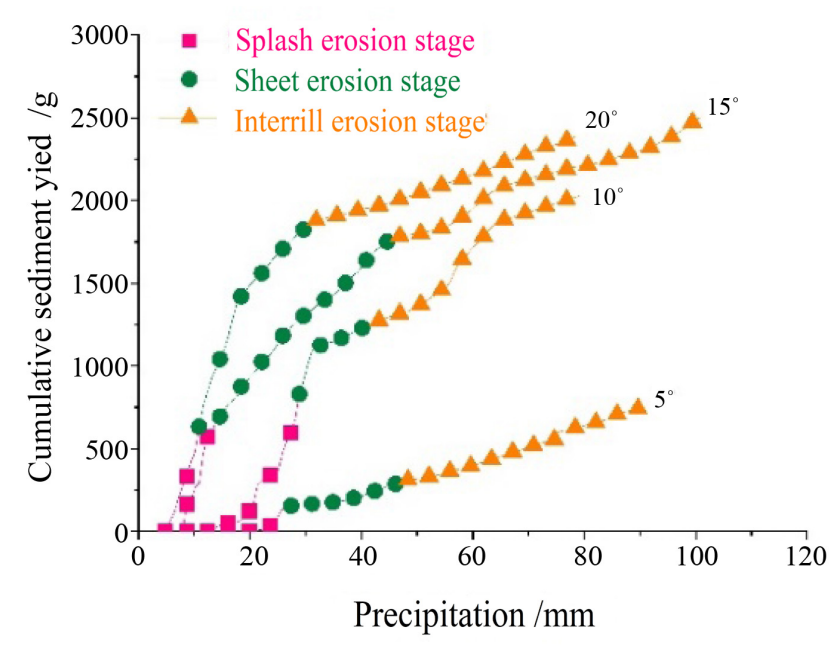

(a)

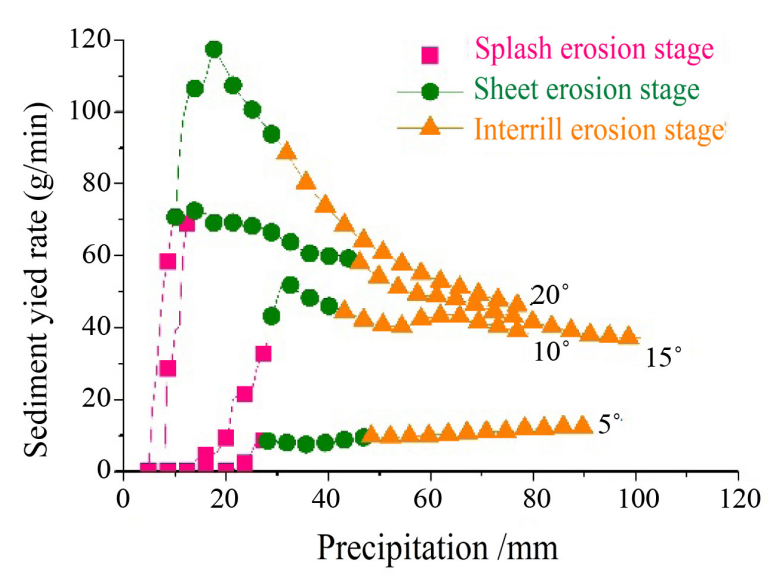

(b)

Figure 3. Evolution of cumulative sediment mass and sediment yield rate as a function of cumulative rainfall for different slope gradients.

whole rainfall event, the evolutions of cumulative sediment mass for different surfaces tended to present similar patterns. At the beginning of rainfall, the sediment mass was $0 \mathrm{~g}$; when runoff initiated, splashes were formed and sediment increased quickly until at a stable level. At the same rainfall intensity, cumulative sediment mass would be greater on a steeper surface and it in all cases would increase quickly and steady off later.

When the rainfall began, the sediment rate was $0 \mathrm{~g} \cdot \mathrm{min}^{-1}$; when the runoff began to generate, the sediment yield rate grew rapidly and peaked. When splash erosion evolved into sheet erosion, the runoff became a sheet of water flow which to some extent reduced the loss of soil and sealing came into being, which prevented sediment from being produced and so diminished the sediment yield rate. On the whole, at the same rainfall intensity, the sediment yield rate was greater for a steeper slope and for each individual curve, sediment yield rate tended to grow quickly at first, then peaked in sheet erosion, and declined gradually to a stable level (Figure 3(b)). The peak sediment yield rate was greater for a surface with bigger slope gradient.

The SPSS regression simulation predicted that the relationship between rainfall and cumulative sediment yield could be represented by the Equation (2):

$$
S_{\text {sediment }}=c_{0}+c_{1} x+c_{2} x^{2}+c_{3} x^{3}
$$

where $c_{0}, c_{1}, c_{2}$, and $c_{3}$ are regression coefficients, $S_{\text {sediment }}$ cumulative sediment yield $\left(\times 10^{-1} \mathrm{~g}\right)$ and $x$ rainfall $(\mathrm{mm})$.

\subsection{Sediment Contribution Rate and Critical Slope Value}

Sediment contribution rate is defined as the ratio of sediment yield for the contouring tillage (CT) surfaces to that of the linear slope (CK) surface. Table 2 shows that in the same erosion process, sediment yield seemed to be higher at a greater slope and it peaked at a $15^{\circ}$ slope and then declined; in the early time of 
Table 2. Changes in contribution of erosion process and slope to sediment yield.

\begin{tabular}{ccccc}
\hline Slope $^{\circ}$ & Erosion process & $\begin{array}{c}\text { CT sediment } \\
\text { yield/kg }\end{array}$ & CK sediment yield $/ \mathrm{kg}$ & $\begin{array}{c}\text { Sediment } \\
\text { contribution rate }\end{array}$ \\
\hline \multirow{3}{*}{5} & Splash & 0.1520 & 0.8713 & 0.1745 \\
& Sheet & 0.1559 & 0.9169 & 0.1700 \\
& Interrill & 0.4379 & 0.4406 & 0.9939 \\
\multirow{2}{*}{10} & Splash & 0.6860 & 0.9584 & 0.7158 \\
& Sheet & 0.5864 & 0.5544 & 1.0577 \\
& Interrill & 0.7549 & 0.4445 & 1.6983 \\
& Splash & 0.6704 & 0.6997 & 0.9581 \\
& Sheet & 1.1096 & 0.8773 & 1.2648 \\
& Interrill & 0.7233 & 0.4693 & 1.5412 \\
& Splash & 0.4775 & 3.3848 & 0.1411 \\
& Sheet & 1.3944 & 1.3690 & 1.0186 \\
& Interrill & 0.5139 & 1.4321 & 0.3588 \\
\hline
\end{tabular}

erosion process, the sediment yield from a CT surface was smaller than that of a CK surface, but at a steeper slope, the CT sediment yield began to increase and catch up with CK sediment yield and finally overtook it. So it could be inferred that there was a critical slope value which influenced sediment contribution rate this way: when at a slope gradient smaller than the critical slope value, the CT sediment yield would obviously be smaller than the CK sediment yield; while at a greater slope value, the CT sediment yield would obviously be bigger than the control's, which meant a bigger contribution rate, even bigger than 1. Figure 2 showed that the contribution of slope and erosion process to sediment yield varied: the rate increased significantly from $5^{\circ}$ to $10^{\circ}$, and after $10^{\circ}$, it increased slowly, which meant there was a minimum increasing rate, and there should be a critical slope value near $10^{\circ}$.

Varied curvilinear regression analyses (linear, log, reciprocal, quadratic, cubic, complex, S, growth and exponential) were conducted to describe the relationship between slope and sediment contribution. The results showed that the relationship could be well represented by a cubic polynomial, and a fitting Equation (3) for prediction was obtained by calculation:

$$
y=0.001 x^{3}-0.030 x^{2}+0.272 x-0.186
$$

According to power rule, if applied twice, function (3) produced second derivative function (4):

$$
y^{\prime \prime}=0.006 x-0.060
$$

If $y^{\prime \prime}=0$, then $x=10$ which meant there was a possible critical slope angle $10^{\circ}$. This calculation was applied to fitting all the erosion processes, and three Perdition functions and critical slopes were produced as shown in Table 3. 
Table 3. The prediction equation and critical slope gradients of different erosion stages.

\begin{tabular}{ccc}
\hline Erosion stage & Prediction equation & Critical slope $^{\circ}$ \\
\hline Splash erosion & $y=-2.851+1.327 x-0.139 x^{2}+0.004 x^{3}$ & 11.58 \\
Sheet erosion & $y=2.481-0.468 x+0.034 x^{2}-0.001 x^{3}$ & 11.33 \\
Interrill erosion & $y=-0.460+0.331 x-0.036 x^{2}+0.001 x^{3}$ & 12.00 \\
\hline
\end{tabular}

\subsection{Surface Area, Volume and Soil Loss}

\subsubsection{Surface Area}

The changes in the area before and after the four stages were shown in Figure 4. All of the 2-D area for the slopes was around $2 \mathrm{~m}^{2}$ (Figure 4(a)), which fell on the range of the surface area defined by DEM point cloud data acquired by an instantaneous digital surface-profile laser scanner. And the 3-D area (Figure 4(b)) generally tended to be greater on a steeper slope and the surfaces in interrill erosion stage had the largest areas. It was concluded that at the same slope gradient, the 3-D area tended to grow with the development of erosion; and in the same erosion stage, the $3-\mathrm{D}$ area increased when the slope gradient increased.

\subsubsection{Surface Volume}

Figure 5 showed that the surface volume continued increasing over the different erosion stages at a slope. At a same erosion stage, the surface volume tended to be smaller when erosion occurred on a steeper slope.

\subsubsection{Erosion Amount}

When compared the measured erosion amount with the calculated erosion amount, it showed that the error would decline over the evolution of erosion which occurred at a same slope. During a same erosion stage, the error tended to increase and then diminish when the slope gradient for surfaces increased. The error between the measured value and calculated value ranged from 0.004 to 0.127 and the average error was 0.053 , which was relatively small. These results proved that the application of 3-D laser scanning techniques allowed more immediate and precise representation of interrill erosion, reflected a more realistic topography and therefore reduced errors.

\section{Discussion}

Tests were conducted on sloped bare surfaces at four gradients on which contour tillage and cumulative rainfall $\left(90 \mathrm{~mm} \cdot \mathrm{h}^{-1}\right)$ were applied, and the evolution of interrill erosion was characterized and analyzed thoroughly.

In the same stages, erosion rate tended to increase first and then decrease when the slope increased. The critical slope values for different stages of splash erosion, sheet erosion and interrill erosion were determined as $11.58^{\circ}, 11.33^{\circ}$ and $12^{\circ}$, with a general possible critical slope $10^{\circ}$ during the whole erosion development process, by operation of regression analyses for sediment contribution rate and slope. However, during the interrill stage, the maximum erosion 


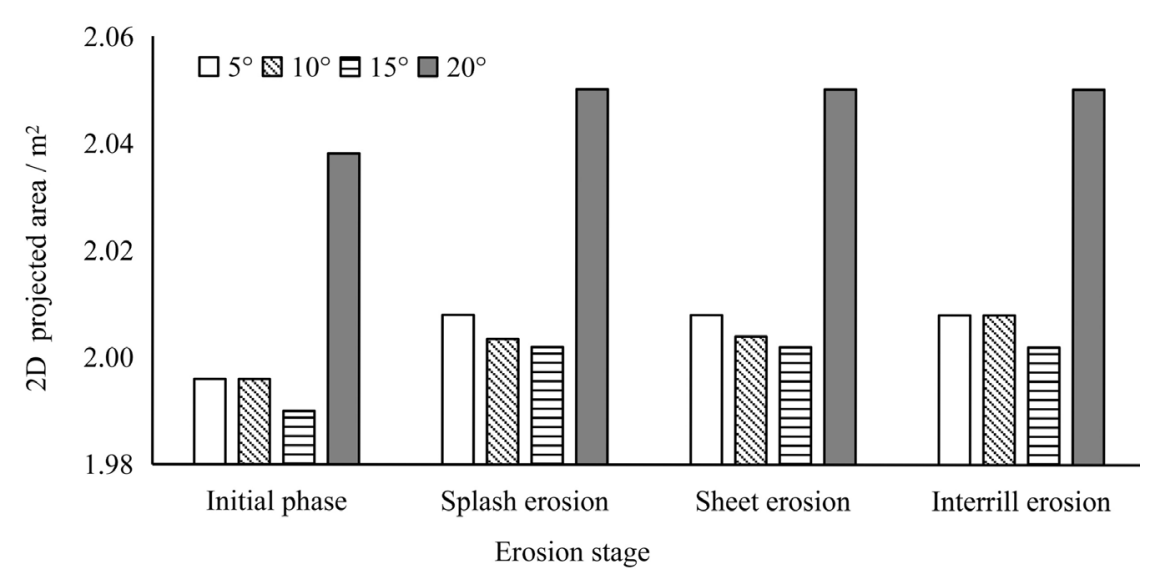

(a)

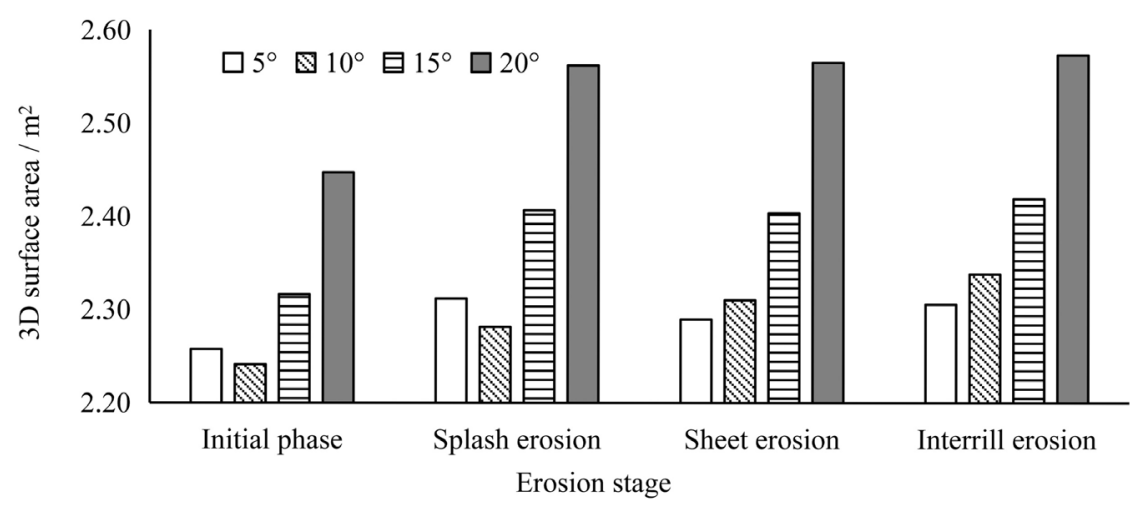

(b)

Figure 4. Changes in projected area for surfaces at each erosion stage for different slopes.

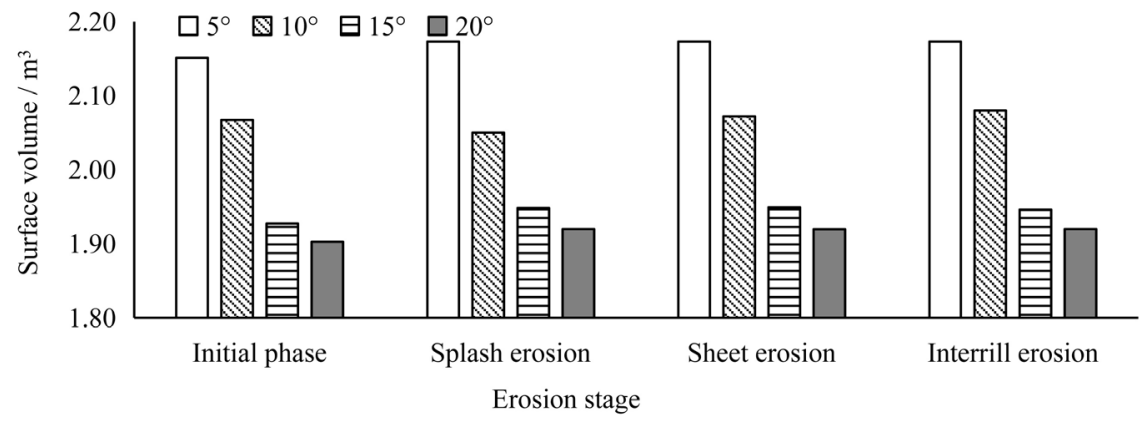

Figure 5. Changes in surface volume at each erosion stage for different slopes.

rate $(2.67 \mathrm{~kg} / \mathrm{min})$ occurred at a $10^{\circ}$ slope gradient, which is more approximate to the critical slope $12^{\circ}$. Therefore, The critical slope value should be further addressed in future research to reduce the gap between the experimental value $10^{\circ}$ and the calculated value $12^{\circ}$, which provides important information for evaluation of land suitability. On the other hand, the critical slope value was obtained with experimental slope length only $2 \mathrm{~m}$, therefore, different slope lengths should be taken into account in the future experiment.

During the same erosion stages, 3-D area of the region of interests increased 
and their surface volume decreased when slope gradient increased. This was because once interrill erosion started to occur on the surface, the erosion would increase multiplefold or even dozen fold [21] [22]. The error between the measured erosion amount and the estimated value ranged from 0.004 to 0.127 with average error 0.053 . The DEM can be safely used to produce precision erosion modelling, clearly reflect detailed morphological characteristics of micro-topographic surface and represent the evolution of erosion.

However, since the tests for this work were carried out under cumulative rainfall, complete interrill erosion processes could not be guaranteed. The scanning of the elevation points on the surfaces could be affected because the intervals between rainfall events could not be controlled precisely for some laboratory and natural factors. Hence, when designing those tests, it is necessary to gain sufficient experience and knowledge by observing the evolution of interrill erosion under a complete rainfall, which could help improve and supplement the current study. Interrill systems on the surfaces are passages for transporting sediments and runoff, so the studies of erosion evolution and hydrologic characteristics are essentially important for water and soil conservation.

Although laboratory rainfall is rather different from natural rainfall, it has many advantages that it is the closest alternative, it can reduce the interval between natural rainfall events, and control the span and timing of an artificial rainfall event.

\section{Conclusions}

Contour tillage is a kind of soil conservation tillage methods along the contour line of topography, enhancing water infiltration and storage capacity, regulating runoff and reducing soil erosion, so as to benefit crop growth and increase yield per unit area. The practice of contour farming mainly applies in rocky mountainous regions where slopes are rather steep with fragmented topography or in areas of Loess Plateau where loss of water and soil is severe. This study established that the critical gradient that a slope has for contour plowing under a rainfall of $90 \mathrm{~mm} \cdot \mathrm{h}^{-1}$ is $10^{\circ}$.

The relationship between the cumulative runoff, sediment yield and the rainfall of microtopographic soil surfaces under different slope gradients could be described by a univariate cubic equation. This study established that the slope gradient was a sensitive factor for microtopographic modeling of erosion prediction and the findings of the dynamics of interrill erosion and sediment characteristics could be used as a basis for future research of erosion prediction and lay the groundwork for conservation of soil and water in the Chinese Loess Plateau. The examination of the critical slope value is important for individuals and government to make informed decisions on land use and to avoid unnecessary waste of resources. The limitations of this research lie with the calculation methods, because only four slope gradients have been considered, and we don't know how close this critical slope is to what we expect to be. To have more pre- 
cise results, we need to try more slope gradients or change our method of calculation. And more experiments and tests are needed to provide more statistical and physical proof to support the existence of such a critical slope in the future.

\section{Funding Acknowledgement Statements}

This work is supported by the National Natural Science Foundation of China (41371273, 41771308).

\section{Conflicts of Interest}

The authors declare no conflicts of interest regarding the publication of this paper.

\section{References}

[1] Gao, H.D., Li, Z.B., Li, P., Jia, L.L. and Zhang, X. (2012) Quantitative Study on Influences of Terraced Field Construction and Check-Dam Siltation on Soil Erosion. Journal of Geographical Sciences, 22, 946-960. https://doi.org/10.1007/s11442-012-0975-5

[2] Fox, D.M. and Bryan, R.B. (2000) The Relationship of Soil Loss by Interrill Erosion to Slope Gradient. Catena, 38, 211-222.

[3] Ribolzi, O., Patin, J., Bresson, L.M., Latsachack, K.O., Mouche, E., Sengtaheuanghoung, O., et al. (2011) Impact of Slope Gradient on Soil Surface Features and Infiltration on Steep Slopes in Northern Laos. Geomorphology, 127, 53-63.

[4] El, K.H., Zhang, H.F., Zhang, P.C. and Mosandl, R. (2013) Soil Erosion and Surface Runoff on Different Vegetation Covers and Slope Gradients: A Field Experiment in Southern Shaanxi Province, China. Catena, 105, 1-10.

[5] Shen, H.O., Zheng, F.L., Wen, L.L., Han, Y. and Hu, W. (2016) Impacts of Rainfall Intensity and Slope Gradient on Rill Erosion Processes at Loessial Hillslope. Soil \& Tillage Research, 155, 429-436.

[6] Zhao, L.S., Wang, L.H., Liang, X.L., Wang, J. and Wu, F.Q. (2013) Soil Surface Roughness Effects on Infiltration Process of a Cultivated Slopes on the Loess Plateau of China. Water Resources Management, 27, 4759-4771. https://doi.org/10.1007/s11269-013-0428-7

[7] Kinnell, P.I.A. and Cummings, D. (1993) Soil/Slope Gradient Interactions in Erosion by Rain-Impacted Flow. Physical Review Letters, 36, 381-387. https://doi.org/10.13031/2013.28349

[8] Koulouri, M. and Giourga, C. (2007) Land Abandonment and Slope Gradient as Key Factors of Soil Erosion in Mediterranean Terraced Lands. Catena, 69, 274-281.

[9] Assouline, S. and Ben-Hur M. (2006) Effects of Rainfall Intensity and Slope Gradient on the Dynamics of Interrill Erosion during Soil Surface Sealing. Catena, 66, 211-220.

[10] Tang, K.L., Zhang, K.L. and Lei, A.L. (1998) Critical Slope Gradient for Compulsory Abandonment of Farmland on the Hilly Loess Plateau. Chinese Science Bulletin, 43, 409-412. https://doi.org/10.1007/BF02883721

[11] Mahmoodabadi, M. and Sajjadi, S.A. (2016) Effects of Rain Intensity, Slope Gradient and Particle Size Distribution on the Relative Contributions of Splash and Wash Loads to Rain-Induced Erosion. Geomorphology, 253, 159-167. 
[12] Li, J.P., Dong, W.G., Meng, H.F. and Jia, M.X. (2016) Research of Rill Erosion Model and Critical Slope Gradient during Rainfall. Journal of Catastrophology, 31, 207-212. (In Chinese)

[13] Wu, L., Peng, M.L., Qiao, S.S. and Ma, X.Y. (2018) Effects of Rainfall Intensity and Slope Gradient on Runoff and Sediment Yield Characteristics of Bare Loess Soil. Environmental Science \& Pollution Research, 25, 3480-3487. https://doi.org/10.1007/s11356-017-0713-8

[14] Zhang, H.H., Ta, N. and Zhang, Q.F. (2016) Spatial Heterogeneity of Loess Contour Tilled Microtopographic Slope in Rainfall Erosion. Soil Science \& Plant Nutrition, 62, 409-415. https://doi.org/10.1080/00380768.2016.1218742

[15] Auerswald, K., Fischer, F.K., Kistler, M., Treisch, M., Maier, H. and Brandhuber, R. (2017) Behavior of Farmers in Regard to Erosion by Water as Reflected by Their Farming Practices. Science of the Total Environment, 613-614, 1-9.

[16] Zheng, Z.C., He, S.Q. and Wu, F.Q. (2014) Changes of Soil Surface Roughness under Water Erosion Process. Hydrological Processes, 28, 3919-3929. https://doi.org/10.1002/hyp.9939

[17] Darboux, F. and Huang, C.H. (2005) Does Soil Surface Roughness Increase or Decrease Water and Particle Transfers? Soil Science Society of America Journal, 69, 748-756. https://doi.org/10.2136/sssaj2003.0311

[18] Gómez, J.A. and Nearing, M.A. (2005) Runoff and Sediment Losses from Rough and Smooth Soil Surfaces in a Laboratory Experiment. Catena, 59, 253-266. https://doi.org/10.1016/j.catena.2004.09.008

[19] Zhou, Z.C. and Shangguan, Z.P. (2007) The Effects of Ryegrass Roots and Shoots on Loess Erosion under Simulated Rainfall. Catena, 70, 350-355. https://doi.org/10.1016/j.catena.2006.11.002

[20] Zhang, Q.F., Wang, J. and Wu, F.Q. (2018) Spatial Heterogeneity of Surface Roughness on Tilled Loess Slopes in Erosion Stages. Soil and Water Research, 13, 90-97. https://doi.org/10.17221/130/2017-SWR

[21] Auerswald, K., Fiener, P. and Dikau, R. (2009) Rates of Sheet and Rill Erosion in Germany: A Meta Analysis. Geomorphology, 111, 182-193. https://doi.org/10.1016/j.geomorph.2009.04.018

[22] Dunkerley D. (2008) Rain Event Properties in Nature and in Rainfall Simulation Experiments: A Comparative Review with Recommendations for Increasingly Systematic Study and Reporting. Hydrological Processes, 22, 4415-4435. https://doi.org/10.1002/hyp.7045 